\title{
DE OUDSTE CACAO-AANPLANT IN SURINAME (1686). \\ DOOR
}

D. S. VAN ZUIDEN.

De cacaocultuur in Suriname wordt door Gouverneur Cornelis van Aerssen van Sommelsdijck voor het eerst ter sprake gebracht in zijn brief aan Directeuren der Societeit van Suriname te Amsterdam van 24 Juli 1687. Zonder dat hij iets vertelt hoe hij er aan gekomen is deelt hij in dit schrijven mede, dat hij vier cacaoboompjes heeft bekomen, die zeer wel groeien. Deze brief handelt voorts o.a. nog over de mislukte ontvluchting van twee uit Holland afkomstige gevangenen, die in de Kolonie waren te werk gesteld en over gewassen, die hij had medegegeven aan zijn zoon François van Aerssen, Heer van Chatillon, die een maand vroeger uit Suriname naar Holland was gekomen.

In Hartsinck's Beschrijving van Guyana komt op pag. 650 de mededeeling voor, dat Françoys van Aerssen, Heer van Chatillon de eerste cacaoboomen mede gebracht heeft naar Suriname na een tocht naar de Orinoquorivier tot het vangen van een paar uit Holland afkomstige strafarbeiders, een onderneming, die, gelet op het gerapporteerde door den Gouverneur in diens schrijven van 24 Juli 1687, door Hartsinck wel onder een vergrootglas schijnt gezien te zijn. Terwijl Hartsinck het medebrengen van die cacaoboompjes dus in verband brengt met deze expeditie, legt Cornelis van Aerssen, hoewel hij beide feiten in zijn schrijven memoreert, daar tusschen geenerlei verband. Hoe het ook zij, Hartsincks mededeeling over 
het medebrengen der cacaoboompjes blijkt juist te zijn.*)

Ik vond namelijk in het protocol van den Amsterdamschen notaris Hendrik Outgers van dato September en October 1696 een verklaring van drie bekende Surinamers, die mij belangrijk genoeg toeschijnt om ze in haar geheel te publiceeren. Zij bevestigt, dat in 1686 bij een tocht naar de Orinoquo Rivier, Franchoys van Aerssen de eerste cacaoboompjes medebracht naar Suriname, die daar snel in aantal toenamen.

Met welk doel deze verklaring werd opgesteld blijkt niet uit de acte.

Op huyden den XXVI September, vijfden en achtsten October eenduys ${ }^{t}$ zes honderd zes en 't negentig, compareerden voor mij Henrick Outgers, notaris publicq binnen Amsterdam in kennisse der naergenoemde getuygen: de heeren Samuel Cohen Nasij, Samuel de la Parre en Herman van Hagen, voor desen alle geresideert hebbende op Suriname, getuygen van competenten ouderdom, ende hebben ten versoecke van d'Hoog Ed. heer François van Aertsen van Sommelsdijck, heer van Sommelsdijck, Plate, Bommel etc. ende Mr. Godefrid Wessem Sintaman, adv ${ }^{t}$ voor de hove van Justitie in Hollant, beijde in hun respective qualiteijten, voor de oprechte waerheijt getuijgt ende verclaert:

Dat in den jaare een duijsent zeshonderd zes en tagentig, den precisen tijdt onbegrepen, den HoogEdelgebooren heer Cornelis van Aersen van Sommelsdijck, Plate, Bommel, Spijk, etc. medeeijgenaer voor een darde part, mitsgaders Gouverneur van de Colonie van Suriname en alsdoen tot Suriname residerende, heeft afgevaerdigt een barck, daerop als hooft gecommandeert heeft den $\mathrm{h}^{\mathbf{r}}$ eerste comparant ${ }^{\mathbf{1}}$ ), zoon van gemelde heer Cornelis van Aersen van Sommelsdijck, bij hem hebbende eenige manschap, mitsgaders ingeladen cargasoenen, die bij hun comparanten niet begroot konnen werden;

dat sij comparanten verstaen hebben, dat gemelde heer eerste

*) Onder de correctie van dit artikel werd mij van vriendelijke zijde medegedeeld, dat in een brief van van Aerssen van Sommelsdijk van 11 Juni 1688 nog voorkomt: ,,vier boompjes cacao, die mijn zoon uit Trinidad hier omtrent de twee jaren gebracht heeft en hier geplant hebben, heeft den eenen nu beginnen vrucht te setten en te dragen sulcx ick te gemoet sie, dat in weynich jaeren de cacao hier oock in groote abondantie wesen sal."

1) Staat comparant, moet zijn requirant. 
DE OUdSTE CACAO-AANPLANT IN SURINAME (1686).

requirant met de voorsz. barque gevaren is naer Rio Orinoque, suijdwaerts de kust van Suriname ende onder het gebiedt van sijn Koninkl. Mait van Spanien gelegen ende gehoorende;

dat gemelde heer eerste requirant aldaer heeft gesocht gehad en ook verkregen een getal cacou-boomen met wortelen met al bequaem om verplant te werden, welcke onderneminge met gevaar van 't leven van den gemelde heer eerste req ${ }^{t}$ was uytgevoert aangesien de strenge wetten onder welcke het vervoeren van cacou-boomen of vruchten bequaem tot verplantinge in de Spaense Westindien (soo sij comparanten meermaal verstaen hebben) verboden is;

dat hun comparanten bekent is dat gemelde heer eerste requirant met vijf van de voorsz. boomen, na hun comparanten best onthoud, tot Suriname is gereverteert; welke boomen alsdoen geplant zijn tot Suriname in den thuyn bij gemelde heer van Sommelsdijck, gouverneur, gebouwt ende gemaeckt, welcken thuyn na de doot van den ged ${ }^{\text {e }}$ heer gouverneur geworden is, soo sij comparanten verstaen hebben, de eijgen thuyn van de societeijt van Suriname, waervan niet meer als twee of drie bomen terecht sijn geraekt en de andere uytgegaen;

dat de voorsz. boomen in vollen groeij met hunne vruchten stonden als den heer van Sommelsdijck voornoemt in den jare een duysent seshonderd acht en tagentig door de rebellerende militie is overvallen ende vermoort;

dat omtrent Maij een duysent zes hondert negen en tagentig, ten tijde als onder 't gouvernement van den $\mathrm{h}^{\mathbf{P}}$ Jan van Scherpenhuijsen eenige France oorlogschepen tot Suriname waren gekomen, om de Colonie ende de forten van dien te vermeesteren, naer dat die afgewesen ende vertrocken waren, den voornoemde $h$, Johan van Scharphuijsen, Gouverneur van de voor z. colonie indertijt de vruchten, die alsdoen rijp op de voorsz. boomen waren ende degene die naderhant daeraan gegroeijt ende rijp geworden zijn, heeft uytgedeelt ende geschonken aan zoodanige planters ende ingesetenen als hem goet docht, die deselve wederom geplant hebben daer het hun behaagde, waerdoor de cacous-boomen in Suriname eerst ingevoert ende aldaar gewonnen sijn en naderhant soo seer vermenigvuldigt dat, na hun comparanten gissinge, nu al eenige duysent boomen aldaer in vollen groeij staen;

dat de voorsz. aanqueekinge van d'uytterste importantie is voor de voorschreve colonie als waer door den handel van cacao in de voorsz. colonie is ingevoert ende gestabilieert, die van seer groot voordeel voor de ingesetenen en eijgenaars van de colonie in 


\section{DE OUDSTE CACAO-AANPLANT IN SURINAME (1686).}

tijden en wijlen soude konnen wesen, als benevens de suykerplantinge selfs.

Gevende voor redenen van wetenschap dat sij attestanten in de voornoemde jaren een duysent seshondert ses en tagentig tot negen en tagentigh en eenigen tijd daernaer op de colonie van Suriname persoonlijck hebben geresideert en al het voor verhaelde met hun kennisse is gepasseert, bereijt sijnde sulx desnoot nader met eede te sterken.

Actum in Amsterdam, present Philip de Marolles en Antonij Adriaensz. als getuijgen.

(Geteekend) Harman van Haagen; Samuel Nassij, Samuel Haim de la Parra, Ph. de Marolle, A. Adriaensz.

H. Outgers, notaris.

P. F. 